\title{
Taylor Scientific Management Theory Carding and Significance of Organization Management
}

\author{
Yimeng Su \\ College of Public Management Administration, Tianjin University of Commerce, Tianjin, China \\ Email address: \\ 987895196@qq.com \\ To cite this article: \\ Yimeng Su. Taylor Scientific Management Theory Carding and Significance of Organization Management. Social Sciences. \\ Vol. 6, No. 4, 2017, pp. 102-107. doi: 10.11648/j.ss.20170604.12
}

Received: June 21, 2017; Accepted: July 12, 2017; Published: July 19, 2017

\begin{abstract}
In the early 20th century, the theory of scientific management was one of the most common management ideas and theories in western industrialized countries. In the production practice, Taylor developed his theory of scientific management through constant scientific experiments and scientific calculation. This theory revolves around the main problem of "improving labour productivity", puts forward about the basic theory of management and organization, mainly including: norm of work, difference piecework system, specialized management function, management exception principle, etc. This paper, through the analysis of the related knowledge of scientific management theory, obtains some points of view and the significance for the management of public organizations in China.
\end{abstract}

Keywords: Taylor, Scientific Management Theory, Organization Management, Reference

\section{Introduction}

As capitalism evolved from the stage of the free competition to the monopoly stage, the scientific management theory began to sprout and form in this context. More than a century later, the rapid development of productive forces of capitalism in the early 20th century, major western capitalist countries successively completed the industrial revolution, the industrial production mode from the small cottage into large scale production factory, complex production process instead of the usual simple manual labor. As competition intensifies, the expansion of production scale, the accuracy of division of functions and the resulting labor conflicts are strongly impact the enterprise original organizational structure and management mode, so how to enhance the production efficiency and management means, to become capitalists increasingly concerned issue, the theory of scientific management evolved in this background. In the early 20th century, the theory of scientific management was one of the most common management ideas and theories in western industrialized countries. It includes a series of scientific methods and theoretical bases for the standardization of production operations and the rationalization of production organizations. Frederick Winslow Taylor is the most famous figure in the school of scientific management and is known as the "father of scientific management". Throughout his life, Taylor was arguably one of America's successful inventors and engineers, he has received about 100 patents in his lifetime, and has been working on time and methods of work since he was 25 . There are many management studies in life, the most representative of his management and organizational thought was the principles of scientific management, published in 1911. The thought of scientific management consists of a series of institutional ideas collectively referred to as the "Taylor system".

\section{The Three Experiments of Scientific Management}

Taylor devote his whole life to improving labor productivity, he passed the spade experiment, carry iron block experiment and metal cutting three experiments, tried to form a job specification, solve the problem of worker sabotage, improve labor productivity.

\subsection{Spade Experiment}

Earlier the workers to work in the factory is himself with a 
shovel, the size of each are not identical, but on different raw materials are used in the same shovels, so when you shovel coal, it's just right, but it's too heavy when you shovel iron. Taylor's study found that when a worker's average load was about 21 pounds per shovel, it was the most productive. So instead of letting the workman bring a shovel, he prepared some different shovels, using different shovels for different ingredients, each carrying a weight of 21 pounds.

The experiment will introduce the experimental method into the management field, developing the potential of people and things, let people do their best is the best way to improve efficiency.

\subsection{Carry Iron Block Experiment}

In 1898, Taylor carried out an experiment in iron handling at Bethlehem steel. When he was in management research, he saw that the company was doing a lot of work, with 75 porters in charge of the work and moving iron pieces to the train. Each iron block weighs more than 80 catties, and the distance is 30 meters. Although each worker works very hard, the work efficiency is not high, and the average person can only carry 12.5 tons of iron. After careful observation, Taylor calculated that a good porter should be able to carry 47 tons of iron a day and not be harmful to health. Taylor science selected workers and training, he picked a strong worker, using money to motivate the worker, according to the regulations of the Taylor, a good approach to handling iron, Taylor's assistant accurately record the worker when transporting iron the time spent on each movement, such as lift iron, stepping out, rest, put down the iron and so on. After a long experiment, the average worker's daily workload surged from 12 tonnes to 48 tonnes a day, and wages increased by 70 percent. The rest of the workers also asked
Taylor to instruct them to use the new work method, and since then, the daily workload of carrying the iron has increased to 47.5 tons.

Based on the experiment of moving iron blocks, it can be concluded that workers are carefully selected and workers know that working hard not only does not harm them, but also gets a lot of salary. Train and help the workers to master the scientific method of work, and have the skills to complete the work quota. The experiment helped workers increase their daily workload by almost three times, and workers' wages has increased, laying the groundwork for a reasonable work quota.

\subsection{Metal Cutting Experiment}

At Midvale steel Works, Taylor studied metal cutting in order to solve the problem of worker sabotage. At this time, Taylor had the knowledge about metal cutting, so he conducted experiments on the efficiency of the lathe operation, which was expected to take six months. In the use of lathe, drilling machine, planer and other machine tool cutting metal, whenever must decide to apply what kind of tool, how much cutting speed, in order to obtain the best metal processing efficiency. The experiment was so complex and difficult that it was expected to take 26 years and cost a huge amount of money, consuming 800,000 tons of steel. In the end, great progress was made with the help of a dozen experts like Bath and White.

The result of this experiment has formed the work specification of metal processing, and found the high speed tool steel which can greatly improve the efficiency of metal cutting, and obtained the data of cutting dosage standard and so on.

Table 1. The three experiments of scientific management.

\begin{tabular}{lll}
\hline Spade experiment & Carry iron block experiment & Metal cutting experiment \\
\hline $\begin{array}{l}\text { The means of experiment shall be introduced } \\
\text { into the field of operation and management }\end{array}$ & Train and help workers get enough skills & The experiment was complex and difficult, it took 26 \\
$\begin{array}{ll}\text { Let people do their best is the best way to } \\
\text { improve efficiency }\end{array}$ & $\begin{array}{l}\text { Let the workers learn the benefits of doing } \\
\text { Standardized management }\end{array}$ & It took a huge amount of money and spend more than \\
Select workers carefully & 800,000 tons of steel. \\
\end{tabular}

\section{The Main Ideas of Scientific Management Theory}

\subsection{Norm of Work}

The key issue around scientific management theory is improving labor productivity. In the United States under the background of that time, because of the experience management that was most prevalent in the enterprise, there was no scientific management method and management method, which was managed by previous work experience. Under this management approach, formed an increasingly prominent contradictions, capitalists can not accurately know the worker's labor efficiency, don't know within the prescribed time, a worker is under normal working conditions and workflow can do how much work, but all too workers work less, get more salary, and then by extending the worker's labor time, increase the intensity of labor to increase the exploitation of workers. And workers don't know how much work they can do in a single day, but they feel they're doing more, but they're paid less. When capitalist unilaterally increase exploitation of workers, workers use the term "Social loafing" as a means of speculative resistance, the situation on the one hand caused the labor efficiency is low, on the other hand also caused the workers' resistance and caused labor conflicts. The best way to resolve this contradiction is to make scientific and reasonable daily work. To make the scientific work of the day, it is necessary to study the steps and actions of the workers precisely through constant scientific experiments and precise calculations. 
Choose appropriate and familiar with the process, high degree of skilled workers, the basic operations used by these people at work processes and tools, and demonstrated with a stopwatch to accurately record the workers to complete each action, procedure time, plus the necessary rest time and the amount of time lost in the process, in the process of the complete and find out the quickest way to do each step, thus it is concluded that the total time required to complete the job, according to these to make a "reasonable days work", this is the principle of the standard of work proposed by Taylor.

\subsection{Difference Piecework System}

Taylor has studied the prevailing wage system in the capitalist enterprises at the time, and based on the previous experience, the difference plan is proposed. Then prevailing wage system, such as daily wage and general piecework wage through detailed analysis, he believes the wage system there are their respective shortcomings, is not very good to motivate the workers, also be no great increase in labor productivity. For example, the enterprise that executes daily wage system, when giving salaries to employees, they are paid according to their duty or position. Even if there is an employee who wants to do something, as time goes on, it will be found that hard work doesn't have any benefit to him, work hard will not increase wages, don't work hard will not be punished, but the best way is to do less as far as possible to maintain the existing position. This gradually lowers the wages of workers, and productivity is not improved. For instance in the enterprise that executes general plan piece wage system, although in a certain range the workers could paid more through their work, but once more than the set range, the capitalists to a greater extent of the extract of the workers' surplus value, will reduce the wage rate, in this case, the workers work harder even, due to lower the wage rates of pay, also can get a bit more than the original daily wages paid. This makes it easier for workers to control the pace of work, keeping everyone's income at the agreed rate. As a result, Taylor put forward the "Difference piecework system" in 1895. Through the study and analysis of man-hours, the method of calculating and calculating the basis of rough estimation and experience was made, and the reasonable quota and the appropriate rate of wage were developed through scientific measurement and calculation. The capitalist takes a different wage rate according to whether the worker has completed the quota, and if the worker is able to meet the quota in quality, he will pay the higher rate when he is paid. If workers didn't finish the job within the scope of work, it is all the work completed by low wage rates of pay, and give a warning to the worker, if still not improve the work efficiency, it is possible to be fired. The difference on piecework wage payment according to the workers, rather than the position, that is to say, everyone get the wage is according to how much he paid labor and skilled degree to calculate, rather than calculated according to the seniority, the purpose of this method is to overcome the phenomenon of the workers "social loafing", and workers' wage rates for high also can arouse the enthusiasm of the work of the workers.

This difference piecework system is conducive to the full mobilization of workers' motivation and productivity. And because the difference plan and the daily wage rate are calculated by scientific calculation, the ability to select the best workers, to be able to do a lot of work, can be more fair.

\subsection{Specialization of Management Functions}

Taylor believes that in practice it is impossible to make the workers plan and execute the work simultaneously, so this kind of contradiction must be addressed by the average distribution of responsibilities between management and workers, to separating the functions of plan and executive function, set up special planning level. In "factory management", Taylor notes that there are 17 major responsible jobs for the designated planning layer, which is essentially separating the management of the organization from the executive function. The management function is undertaken by the management and the workers are responsible for the specific execution.

It is not only the separation of plan function and executive function, but also the "Function length system" should be carried out in the organization. He thought at the time of military management in the enterprise, the command after assigning to the workers there, then the heads of the shoulder function is extremely complex, a leader needs to have a variety of quality at the same time, and can't be happened to every leader in the workshop has each kind of quality. Therefore, in order to make the function of the foreman effective, the function of the foreman should be further refined, for each of the foreman to undertake only one specific function. On this basis, Taylor designed eight functions, used instead of the original factory group leader. Each worker can issue orders to the worker within the scope of his or her duties, but the different managers collaborate with each other in order to give orders to the workers.

Taylor believes that this kind of functional work is a good way to make full use of everyone's expertise, and that each worker's responsibilities are clear, which can improve management efficiency and reduce the cost of training. But although function length system has many advantages, but this kind of simple functional structure, the process of management in the real, is very easy to create the situation with multiple management and conflicting policies from different departments, cause the confusion of management. So the idea is not actually implemented in reality.

\subsection{Principle of Management Exception}

Exception principle refers to the senior management personnel in the organization should have a regular daily transaction authorization to subordinate managers to do, but we only responsible for the exceptional items, that is, for the long-term development of some important decisions about organization and management, for example involves the enterprise development strategy and the rotation of top 
management. Taylor in his book "factory management" has pointed out: "the manager only accept the extraordinary or standard all exceptions, especially good and special bad exceptions, generality, compression and more report, the major policies so that he can have time to think about and study his important personnel's character and suitability". This principle of management exception evolved over time into the authorization principle, decentralization principle and division of the management method.

\section{The Significance of Scientific Management Theory}

In a time when science and technology are so advanced, the principles of scientific management still have some implications for the management of our public organizations today.

\subsection{Workflow Standardization}

Now more and more developed science and technology, production and more advanced hardware equipment, therefore the organization's hardware facilities to strictly according to the requirements of scientific standardization, meet the needs of the production of each link; not only that, the organization's hardware equipment is up to the standard, and the employees are able to use scientific and unified equipment and manufacturing process specifications at work, which can greatly improve the efficiency of the work. With the progress and development of science and technology, in today's organizations, the proportion of brain labor is increasing. This means that the meaning of standardization varies according to the nature of the organization. In the organization of mental labor, Taylor's theory of scientific management inspired us to standardize the work process. We can break down each task into a small task, a small goal by working analysis, standardization process required to complete the work is specified, striving for every step is the simplest scientific way to accomplish this task. And according to the different job nature, define different task goals, complete the job description and qualification for each post standardization. Ensure that every job is staffed by employees who are capable of doing the job. According to the normalized workflow, each work is completed and the work efficiency is improved.

\subsection{Specialization of Functions}

An organization that has adequate hardware facilities is not enough, and a reasonable organizational structure should be established. In order to organize the internal organization, establish the appropriate responsibility system, keep the communication flow smoothly, and cooperate with each other is the most basic requirement. With the continuous development of productive forces, the size of the organization is more and more big, the work of various departments is becoming more and more complicated, the organization's senior management shall be responsible for the macro issues related with the organization's strategic development, and the operation of the grass-roots staff should do her own work. Different people in different positions do their job and cooperate with each other, such not only can effectively improve the labor productivity, and make each employee to reach his maximum value, finally realizes the benign operation and long-term development of the organization.

\subsection{Employee Training Falls into Place}

Human resources are the most precious resources, and the organization's employees are the soul and core competencies of an organization. In his theory of scientific management, Taylor used to "select the first class workers" and teach them to master the scientific method of work, and to do the quota day work according to the scientific method. This means that selecting the best employees can greatly increase the productivity of the labor force, and the people will do their best. In today's organizations, to timely find the staff's requirements, the employees necessary pre-job training and skill training, on the one hand, can help employees improve their working skills, realize self development; On the other hand, when employees' ability to ascend, and can promote production efficiency, bring more profit for organization, enhance the overall competitiveness of the organization, realize the employees and the common progress of the organization.

\subsection{Organization Authority Rationalization}

Taylor had referred to in the principles of scientific management management exception principle, the organization's senior management personnel in charge of important decision-making, only the daily things to the managers to do below, is today's authorized principle. In a modern organization, if the organization all the decision-making power is concentrated in the hands of a few senior managers, because of limited time and energy, senior management personnel, organization all big and small, such as the approval of the executive decision time will increase a lot, not only reduces the working efficiency, and once when a decision-making errors, the whole organization can not operate properly. As a result, the organization's senior managers should be proper devolution of power to middle managers, some transactions in the department to delegate to the department manager to decide head of the department of business is more understanding, can make a more suitable for the department of strategy, and decision-making time is short, and supervise the implementation process and timely correcting, and feedback quickly. This can reduce the burden of senior managers and enable them to focus on the strategic development of the organization; It can also enhance the sense of responsibility and belonging of middle managers, arouse the enthusiasm of the work, and realize the positive interaction and orderly operation of the organization.

\subsection{Organization Incentives to Diversify}

In order to motivate workers to work hard and meet their 
quota workload, Taylor has proposed a different accounting system for workers who complete or overdo their work and pay a high wage rate. It also has implications for today's organization's compensation management. In order to encourage employees to do their work on time, they can make corresponding incentives. But when it comes to incentives, I think that the real needs of employees should be paid attention to, and the incentives are needed. For employees who wish to receive material rewards, they may be given appropriate rewards if the work is done well. But for those who aspire to self-fulfillment, consider offering training opportunities, gaining more skills, or offering a promotion to a slightly higher position to achieve self-development. I think we should also pay attention to the combination of material and mental stimulation, to pay attention to the mental needs of employees and to create a good organizational atmosphere and culture. And provide a comfortable working environment for employees to improve their motivation and efficiency.

\section{Conclusion}

Taylor has his own experience working in the first line of the factory, use of scientific methods, gradually formed the scientific management theory, bringing science into the management field, instead of the traditional management methods rely on personal experience; and distinguish the management function from the executive function, which provides the basis for the specialization of functions. But Taylor's view of workers may be too absolute. He thinks people are "economic people", and workers are only concerned about improving their own money, and indifferent to other things. The hypothesis was not until Mayo conducted the Hawthorne experiment to suggest that the "social human" hypothesis was denied. I think human's demand is complex and diverse, a person at different times have different requirements, so should use the dialectical view to look at this problem, according to the different needs of people, to take the corresponding management methods. And scientific management, although stressed people post match, more focus on jobs, rather than people, each post have standardized operation process and method, the workers have to do is training well according to the standard operation procedure to finish work, but in today's knowledge economy era, the staff engaged in mental labour, have no fixed standardization process, practice of this management mode. Therefore, we should pay more attention to the role of human beings, formulate corresponding incentives, maximize the potential of people, and enhance the competitiveness of organizations.

Taylor's scientific management theory in today still has considerable significance to our country organizations, the main problem of the scientific management theory proposed by Taylor is how to improve the efficiency of labor production. And around that central question he put forward norm of work, difference piecework system, specialized management function, management exception principle, etc. In the current organizational management, it is still possible to draw lessons from scientific management theory to guide the practice of organizational management in China, but our country groups are rooted in the soil of the motherland to grow up, so I think in the western management thoughts, should be combined with China's specific national conditions, taking into account the context of the organization's survival and development, it is an organization's survival and development environment. We must firmly grasp the premise of the environment and use scientific management theory to guide the management practice of the organization. At the same time, it should also take into consideration whether the organization culture and atmosphere of the organization are suitable, according to the organization's goal, the corresponding management style.

\section{References}

[1] Taylor. In the United States congressional testimony [M]. Beijing: China social sciences press, 1984.

[2] Frederick Taylor, Huang Zhen translation. Scientific management principle [M]. Beijing: Beijing university of science and technology press, 2012.

[3] Taylor. Piecework wage system [M]. Shanghai: Shanghai science and technology publishing house, 1984.

[4] Ping-ping Nie, Li-min Yin. Public organization theory Wuhan: Wuhan university press, 2009.

[5] Xin-chun Li, Xiao-hong Hu. Principles of scientific management: the theory of reflection and critique of reality $[\mathrm{J}]$. Journal of management, 2012, pp.658-670.

[6] Ze-xin Zhou, Zheng-gang Song. The institutional value of scientific management --to mark the 100th anniversary of the Taylor "principles of scientific management" appeared $[\mathrm{J}]$. Journal of modern finance and economics (journal of Tianjin university of finance and economics), 2011, pp.87-92+119.

[7] Luo Min. The legacies of Taylor scientific management and its reflections, and to commemorate the 100th anniversary of the "principles of scientific management", $[\mathrm{J}]$. Journal of foreign economics and management, 2011, pp.1-10.

[8] Chun-hua Chen. Taylor and labor productivity-written in the book "principles of scientific management" the birth of one hundred [J]. Management world, 2011, pp.164-168.

[9] Xiang-nan Tao, Ya-jun Zhou, Chen Yao. The scientific name of competition for control of the workshop Taylor "principles of scientific management", the new interpretation [J]. Journal of Xue Hai, 2013, pp.118-126.

[10] Jun-feng Ma, Jun-ying Deng, Zhi-liang Chen. Reinterpret Taylor scientific management principle [J]. Journal of academic BBS, 2005, pp. 7-11.

[11] Fa-qiong Yang, Zhi-feng $\mathrm{Wu}, \mathrm{Y}$ ang Min. The second industrial revolution in the United States and the economic growth logic behind Taylor system and Ford system [J]. Time finance, 2017, (02): 13-14.

[12] Lei-ming Zhang. Detailed management of "trilogy" [J]. Communist party member (Hebei), 2016, (27): 32-33. 
[13] Fu-ren Zhang. The thinking of Taylor's scientific management theory--Taking Foxconn's jump event as an example [J]. Management, 2016, (25): 108.

[14] Zhou Jie. The advantages and disadvantages of Taylor scientific management theory [J]. Science and technology, 2016, (18): 183-184

[15] Wei-kang Li, Yong-shun Liu. From the perspective of "human nature", the development of management theory [J]. Chinese and foreign entrepreneurs, 2016, (17): 233.

[16] Li-li Zuo. The implications of scientific management on contemporary human resource management [J]. Theory, 2016, (06): 112-113.

[17] Huai Hong. A study on the management thought of Taylor system [J]. Shang, 2016, (21): $157+126$.

[18] Gong Wei. The influence of the "father of scientific management" on the development of Chinese management [J]. Shang, 2016, (17): 89.

[19] Su-bin Zhang. Discussion on the practical application of scientific management thought $[\mathrm{J}]$. Enterprise guide, 2016, (04): 33.

[20] Lan-hui Liu. Standardization is the basis of management [J]. China health quality management, 2016, (01): 8 .

[21] Li Juan. The development of western management ideas in the perspective of "human nature hypothesis" [J]. Economic and trade practice, 2015, (10): 223.
[22] Hao-xue Li, Ming-wan Yang, Liang-zhu Yan. The enlightenment of tailuo scientific management theory to China's administrative management $[\mathrm{J}]$. Chinese and foreign entrepreneurs, 2015, (23): 47.

[23] Chun-xiong Liu. "scientific management" failed? [J]. Chinese and foreign management, 2015, (06): 66-68.

[24] Kang Rui. A brief discussion on Taylor's scientific management theory [J]. Brand, 2015, (04): 87.

[25] Jin-feng Xiao, Chun-yi Liu. A further understanding of scientific management [J]. Management, 2015, (08): 212.

[26] Hai-tao Chen. Status and trend of management development $[\mathrm{J}]$. Chinese and foreign entrepreneurs, 2014, (34): $89+91$.

[27] Wang Ting. The contribution of scientific management to public administration [J]. Management observation, 2014, (30): $38-40$.

[28] Fa-Sheng Yuan. Discussion on management institutionalization and humanization [J]. Shanghai business, 2014, (07): 65-68.

[29] Li-Hua Ma. Management classic dialectical application [N]. China joint business daily, 2014-01-20 (B03).

[30] Hong-yu Zou. The role of scientific management in enterprise management and reform [J]. Enterprise reform and management, 2014, (18): 15-16. 